\title{
Clinical and epidemiological features of tuberculosis in children and adolescents
}

\author{
Características clínicas e epidemiológicas da tuberculose em crianças e adolescentes \\ Características clínicas y epidemiológicas de la tuberculosis en niños y adolescentes
}

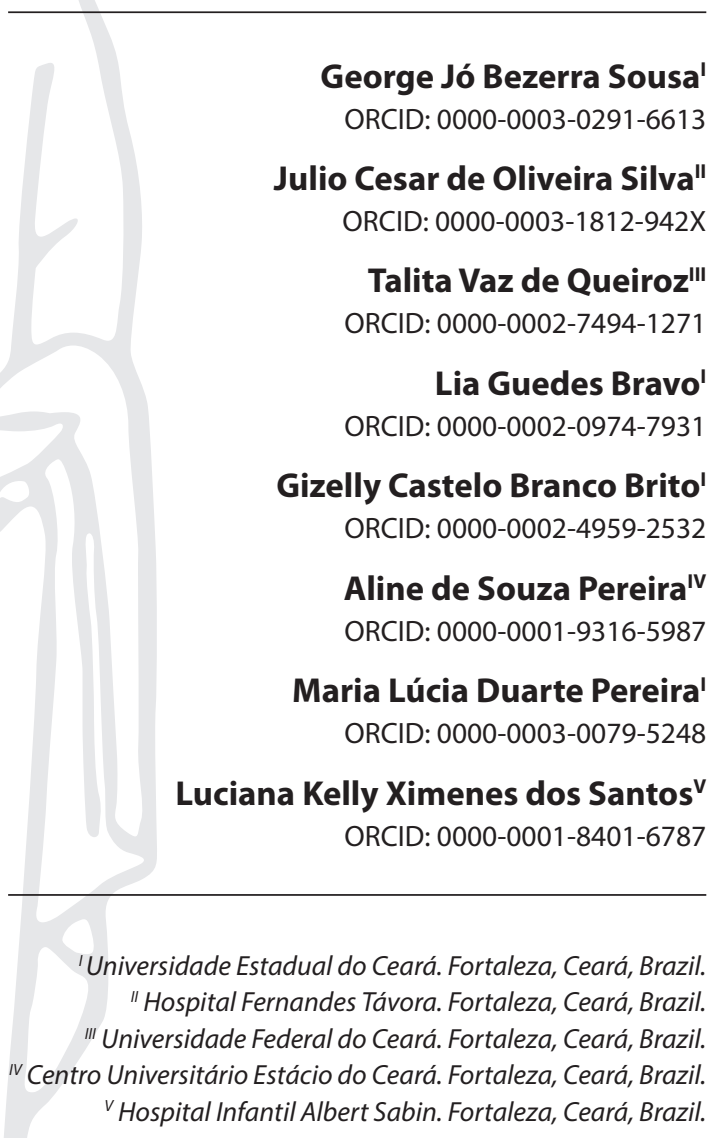

How to cite this article:

Sousa GJB, Silva JCO, Queiroz TV, Bravo LG, Brito GCB, Pereira AS, et al. Clinical and epidemiological features of tuberculosis in children and adolescents. Rev Bras Enferm. 2019;72(5):1271-8.

doi: http://dx.doi.org/10.1590/0034-7167-2018-0172

Corresponding Author:

George Jó Bezerra Sousa

E-mail: georgejobs@hotmail.com

\begin{abstract}
Objective: To analyze the clinical and epidemiological features of tuberculosis in children and adolescents in an infectious diseases reference hospital. Method: A documental and retrospective study was carried out with 88 medical files in an infectious diseases reference hospital in the state of Ceará. Data were analyzed by univariate, bivariate and multivariate approaches. Results: It was found that, depending on the tuberculosis type, its manifestations may vary. The logistic regression model considered only pulmonary tuberculosis due to a number of observations and included female sex (95\% Cl: 1.4-16.3), weight loss (95\% Cl: 1.8-26.3), bacilloscopic screening (95\% Cl: 1.5-16.6) and sputum collected (95\% Cl: 1.4-19.4) as possible predictors. Conclusions: Children and adolescents present different manifestations of the disease depending on the tuberculosis type that affects them. Knowing the most common features of each condition could enhance early diagnosis and, consequently, result in adequate treatment and care.

Descriptors: Tuberculosis; Child; Adolescents; Epidemiology; Pediatric Nursing.
\end{abstract}

\section{RESUMO}

Objetivo: Analisar as características clínicas e epidemiológicas da tuberculose em crianças e adolescentes de um hospital de referência em doenças infecciosas. Método: Foi realizado um estudo documental e retrospectivo com 88 prontuários médicos em um hospital de referência em doenças infecciosas no estado do Ceará. Os dados foram analisados através das abordagens univariada, bivariada e multivariada. Resultados: Verificou-se que, dependendo do tipo de tuberculose, suas manifestações podem variar. O modelo de regressão logística considerou apenas a tuberculose pulmonar devido a um número de observações e incluiu sexo feminino (IC 95\%: 1,4-16,3), perda de peso (IC 95\%: 1,8-26,3) e baciloscopia (IC 95\%: 1,5-16,6) com coleta de escarro (IC95\%: 1,4-19,4) como possíveis preditores. Conclusão: Crianças e adolescentes apresentam diferentes manifestações da doença dependendo do tipo de tuberculose que os afeta. Conhecer as características mais comuns de cada condição pode melhorar o diagnóstico precoce e, consequentemente, levar a tratamentos e cuidados adequados.

Descritores: Tuberculose; Criança; Adolescentes; Epidemiologia; Enfermagem Pediátrica.

\section{RESUMEN}

Objetivo: Analizar las características clínicas y epidemiológicas de la tuberculosis en niños y adolescentes en un hospital de referencia de enfermedades infecciosas. Método: Se realizó un estudio documental y retrospectivo con 88 archivos médicos en un hospital de referencia de enfermedades infecciosas en el estado de Ceará. Se analizaron los datos por enfoques univariados, bivariados y multivariados. Resultados: Se encontró que, dependiendo del tipo de tuberculosis, sus manifestaciones pueden variar. El modelo de regresión logística consideró solo la tuberculosis pulmonar, debido a varias, observaciones e incluyó el género femenino (IC 95\%: 1,4-16,3), la pérdida de peso (IC 95\%: 1,8-26,3), la revisión baciloscopia (95\% Cl: 1,5-16,6) y el esputo recolectado (95\% Cl: 1,4-19,4) como posibles predictores. Conclusiones: Los niños y adolescentes presentan diferentes manifestaciones de la enfermedad en función del tipo de tuberculosis que los afecta. Conocer las características más comunes de cada afección podría mejorar el diagnóstico temprano y, en consecuencia, resultar en un tratamiento y atención adecuados. Descriptores: Tuberculosis; Niño; Adolescentes; Epidemiología; Enfermería Pediátrica. 


\section{INTRODUCTION}

Tuberculosis (TB) is a known tropical infectious disease and currently is the number one cause of death among the infectious conditions. In 2016, there was estimated 10.4 million new cases of TB all over the globe, and $6.9 \%$ of these cases were represented by people under 15 years old ${ }^{(1)}$. During the same year in Brazil, an incidence rate of 32.4 new cases of TB per 100 thousand habitants was identified. No data were available regarding manifestation in children or adolescents'(2).

Only recently did the World Health Organization (WHO) begin publishing data from this specific group. Following WHO initiative, many countries started publication on the childhood results from their TB programs; however, information on the subject is still scarce and several questions have not yet been addressed. Challenges such as early and/or proper diagnosis, early treatment and adequate notification difficult the publication of accurate data ${ }^{(3)}$.

It is important to consider that TB in children varies from the adult manifestation of the disease in several ways. Some studies ${ }^{(4-5)}$ presented the differences between both types; for example, in children and adolescents, the history of contact is positive over $50 \%$ of the cases, contrasting with adults, which is negative. Although some clinical clues such as chronic cough and fever are present in both cases, children present weight loss or failure to thrive; and in adults, the weight loss is uncommon. Differently from adult $T B$, in children, hemoptysis is rare.

Even though little is known about the disease, the Brazilian literature still lacks in publications about this subject. One study reported that this difficulty in finding childhood cases occurs due to the many ways in which the disease is perceived, as well as the low number of professionals and few tools available for the task. All these situations can lead to underreporting of the disease ${ }^{(6)}$.

Furthermore, it is possible to identify that, depending on the Brazilian region, incidence of the disease may vary considerably and, as previously stated, this can be due to the unusual form that the disease appears in this particular group ${ }^{(7)}$. Because of this, it is very difficult to generalize the research results since the scenarios are completely different from each other.

By gathering these pieces of information, it can be seen that TB in children and adolescents is a serious concern, which brings the need for a qualified health team and appropriate care. Among health professionals, nurses are involved in several activities related to care towards people with such condition. Directly observed treatment, home visits and pre- and postconsultations are actions mostly focused on the nursing team ${ }^{(8)}$. Although much is known about TB and the importance of nurses in the management of this illness, nursing professionals still perceive the disease with stigma and fear, which contributes to distance towards patients ${ }^{(9)}$.

Nevertheless, considering the important role that TB has in the health-illness process of developing countries and its relevance when analyzing the scarce Brazilian publication about the disease in children and adolescents, the importance of conducting researches in this field is evident. Since TB in this age group is becoming more common, it is vital that health professionals, including nurses, know aspects involving TB in the young population. Thus, more knowledge on this area would give a clear vision to them about what features are expected in different TB types, which could enhance identification of the disease in early stages.

\section{OBJECTIVE}

To analyze the clinical and epidemiological features of tuberculosis in children and adolescents in an infectious diseases reference hospital.

\section{METHOD}

\section{Ethical aspects}

This research was submitted to the Brazilian Platform of Research Involving Human Beings and was approved by its Ethics Committee as well as by the hospital in which the research was conducted. Confidentiality was guaranteed to each person whose medical file was used, and only data that were relevant to this study was gathered as established in the $466 / 12$ resolution of the Brazilian National Health Council.

\section{Design, location of the study and study period}

This documental and retrospective study used medical files to investigate the characteristics associated with TB in hospitalized children and adolescents. The research was conducted in a tertiary healthcare hospital, located in the municipality of Fortaleza, a reference in treating infectious diseases in the state of Ceará, Northeast Brazil.

Most of its patients are from Fortaleza, but there is also a number of them from countryside cities and even people from other states. It is also an institution for teaching and research purposes. There are different types of services offered in the hospital, such as intensive care, outpatient following, and services directed to specific groups such as children and adolescents. The hospital's pediatric unit admits people from zero to eighteen years with infectious conditions requiring a specific health assistance.

Moreover, this institution also has an area destined to file all records known as Medical and Statistical Archive Service. It was developed to properly allocate the files and use them for further case investigation and outpatient following. It is also used for scientific reasons, under the ethical committee approval, the researchers can access them and retrieve necessary data.

This study was conducted in the Medical and Statistical Archive Service from June to July 2016.

\section{Population and sample}

All medical files from people aged zero to eighteen years that were hospitalized to receive treatment for any type of TB from January 2010 to December 2015 available during data collection period were included. No medical file was excluded from data collection.

The decision for this age range was given by the Brazilian Statute of the Child and Adolescent (In Portuguese: Estatuto da Criança e do Adolescente-ECA). The document considers a child a person until 11 years and 29 days old, and a person from 12 to 18 years old is considered an adolescent ${ }^{(10)}$. 


\section{Study protocol}

At this service, it is possible to find books that are annually made, called "Discharge and Deaths Book" (In Portuguese: Livro de Altas e Óbitos), containing the first information for each person hospitalized such as name, age, sex, final diagnosis, outcome and medical file number. Only age and final diagnosis were taken into consideration, since only the files from people with TB aged until 18 years were able to participate in the research. Thereafter, the numbers of each medical file were used to find the records and start data collection.

A total of 88 medical files was found that fit the previously cited criteria and were thus used to have their data extracted. In this part of the research, a structured instrument developed by the authors was used to gather information. This instrument covered different features that were hypothesized as being associated with the disease (sociodemographic, clinical, laboratory and outcome).

\section{Analysis of the results and statistics}

This paper covers features associated with TB in children and adolescents that included several different aspects. For such, all the clinically important variables passed by statistical analysis with the different TB diagnosis, which were also found in the files.

The variables were analyzed using the application SPSS version 20.0. Univariate, bivariate and multivariate analysis were performed in this study. Firstly, descriptive statistics was used, mostly by using absolute and relative frequencies of the variables. Afterwards, all nominal variables were associated with the different TB diagnosis; for this, the chi-square test was performed (or Fisher's exact test when there were less than five observations in the cells), statistical significance was considered when $P<0.05$. For the multivariate models, performed logistic binary regressions were performed considering the outcomes of TB diagnoses. For this, we considered the results of $P<0.20$ and integrated them into the first models for each diagnosis; however, only those with $P<0.05$ remained in the final model. For bivariate and multivariate approaches, it was also considered a 95\% Confidence Interval $(95 \% \mathrm{Cl})$.

\section{RESULTS}

During January 2010 to December 2015, eighty-eight children and adolescents were admitted to the institution to treat TB; thus, these number medical files were used for the research. In this research, it was considered two different age ranges ( $\leq 10$ years old and $>10$ years old) because, for the Brazilian Health Ministry, from 10 years old, TB is similar to the adult form of the disease ${ }^{(11)}$.

From them, it was possible to see that $56 \%$ of the children and adolescents were male, $73 \%$ pardo ${ }^{1}, 69 \%$ from the countryside, and $84 \%$ with more than 10 years old. The most common diagnosis was pulmonary TB $(59 \%)$, followed by extrapulmonary TB $(25 \%)$, mixed type TB (13\%) and drug-resistant TB (3\%).

The description of the features associated with diverse TB types is presented in Tables 1 to 4 . In Table 1, it can be seen the features associated with pulmonary TB. Being female, presenting

1 Brown-skin color expectoration, weight loss and performing bacilloscopic screening with sputum were associated with the previously cited condition. Highlighting that the female sex had almost three times more odds of pulmonary TB and manifestations such as expectoration and weight loss were almost five times more associated with the pulmonary manifestation of the disease.

Table 1 - Association of children and adolescents' features and pulmonary Tuberculosis registered in the medical files, Fortaleza, Ceara, Brazil, 2018

\begin{tabular}{|c|c|c|c|c|}
\hline \multirow{2}{*}{ Features } & \multicolumn{2}{|c|}{ Pulmonary TB } & \multirow{2}{*}{$p$ value } & \multirow{2}{*}{$\begin{array}{c}\text { Odds Ratio } \\
(95 \% \mathrm{Cl})\end{array}$} \\
\hline & No (\%) & Yes (\%) & & \\
\hline Sex $(\text { Female })^{*}$ & $11(28.2)$ & $28(71.8)$ & 0.03 & $2.65(1.08-6.48)$ \\
\hline Age Range (>10 years old $)^{*}$ & $29(39.2)$ & $45(60.8)$ & 0.45 & $1.55(0.49-4.88)$ \\
\hline Skin Color (Pardo) ${ }^{* a}$ & $25(39.1)$ & $39(60.9)$ & 0.56 & $1.32(0.51-3.40)$ \\
\hline Precedence (from Fortaleza) ${ }^{*}$ & $11(39.3)$ & $17(60.7)$ & 0.83 & $1.10(0.44-2.75)$ \\
\hline Basic Sanitation $^{+}$ & $19(46.3)$ & $22(53.7)$ & 1.00 & $\neq$ \\
\hline Fever* & $23(35.4)$ & $42(64.6)$ & 0.07 & $2.37(0.90-6.25)$ \\
\hline Expectoration* & $15(27.3)$ & $40(72.7)$ & 0.001 & $4.66(1.85-11.76)$ \\
\hline Weight Loss* & $5(17.9)$ & $23(82.1)$ & 0.003 & $4.91(1.65-14.64)$ \\
\hline Dyspnoea* & $5(33.3)$ & $10(66.7)$ & 0.51 & $1.47(0.45-4.75)$ \\
\hline Lymph Nodes Alteration ${ }^{+}$ & $6(100.0)$ & $0(00.0)$ & 0.004 & $\neq$ \\
\hline $\mathrm{HIV}^{+}$ & $4(57.1)$ & $3(42.9)$ & 0.43 & $0.49(0.10-2.33)$ \\
\hline Comorbidities* & $14(43.8)$ & $18(56.2)$ & 0.68 & $0.83(0.34-2.00)$ \\
\hline Previous TB treatment ${ }^{*}$ & $13(37.1)$ & $22(62.9)$ & 0.55 & $1.29(0.54-3.11)$ \\
\hline Bacilloscopic screening* & $11(22.4)$ & $38(77.6)$ & $<0.001$ & $6.16(2.41-15.74)$ \\
\hline Mycobacterium culture* & $23(45.1)$ & $28(54.9)$ & 0.34 & $0.65(0.27-1.57)$ \\
\hline Tuberculin skin test* & $17(47.2)$ & $19(52.8)$ & 0.31 & $0.64(0.27-1.52)$ \\
\hline Sputum collected* & $15(26.3)$ & $42(73.7)$ & $<0.001$ & $5.88(2.26-15.30)$ \\
\hline Bronchoalveolar liquid collected $^{+}$ & $0(00.0)$ & $4(100.0)$ & 0.14 & $\neq$ \\
\hline Outcome (hospital discharge)* & $30(41.1)$ & $43(58.9)$ & 0.93 & $0.95(0.30-2.96)$ \\
\hline
\end{tabular}

Note: ${ }^{*}$ chi-square; ${ }^{\dagger}$ Fisher's exact test; ${ }^{\ddagger}$ Not possible to calculate due to low values in the matrix TB-Tuberculosis.

The next table (Table 2) shows the features associated with extrapulmonary TB. Statistical significance was found for expectoration, weight loss, previous TB treatment, bacilloscopic screening and sputum collected as protective factors, but it is important to note that they are in this situation because they are risk factors to pulmonary TB. Being from Fortaleza and performing the tuberculin skin test are positively associated with extrapulmonary TB. Moreover, it was not possible to calculate both odds ratio and $95 \%$ confidence interval to lymph node changes due to the values in the matrix; however, the six patients that presented such a condition were diagnosed with extrapulmonary manifestation. Therefore, such condition was considered as a possible predictor of extrapulmonary TB.

In Table 3, we presented the results of the mixed-type TB, in other words, both pulmonary and extrapulmonary TB. In this case, being pardo was considered as protection factor, so people with other skin colors have more odds of this disease. Only HIV had a positive association with it ( $p=0.004$ ) with high odds to this TB type (around 14 times).

Table 4 presents data of drug-resistant TB in children and adolescents. It was not possible to find statistical significance to resistant forms of TB, but previous TB treatment nearly approached a significant contribution to developing resistance to medication $(p=0.06,95 \% \mathrm{Cl}: 0.98-1.21)$. Although it is not a positive measurement, it should be taken into account for this specific type of TB. 
Table 2 - Association of children and adolescents' features and extrapulmonary Tuberculosis registered in the medical files, Fortaleza, Ceara, Brazil, 2018

\begin{tabular}{|c|c|c|c|c|}
\hline \multirow{2}{*}{ Features } & \multicolumn{2}{|c|}{ Extrapulmonary TB } & \multirow{2}{*}{$\begin{array}{l}p \\
\text { value }\end{array}$} & \multirow{2}{*}{$\begin{array}{l}\text { Odds Ratio } \\
(95 \% \mathrm{Cl})\end{array}$} \\
\hline & No (\%) & Yes (\%) & & \\
\hline Sex $(\text { Female })^{*}$ & $33(84.6)$ & $6(15.4)$ & 0.06 & $0.37(0.13-1.07)$ \\
\hline Age Range ( $>10$ years old $)^{*}$ & $57(77.0)$ & $17(23)$ & 0.31 & $0.53(0.15-1.81)$ \\
\hline Skin Color $(\text { Pardo })^{*}$ & $47(73.4)$ & $17(26.6)$ & 0.58 & $1.37(0.44-4.25)$ \\
\hline Precedence (from Fortaleza) ${ }^{*}$ & $17(60.7)$ & $11(39.3)$ & 0.03 & $2.88(1.05-7.84)$ \\
\hline Basic Sanitation $^{+}$ & $30(73.2)$ & $11(26.8)$ & 1.00 & $\neq$ \\
\hline Fever* & $51(78.5)$ & $14(21.5)$ & 0.20 & $0.51(0.18-1.45)$ \\
\hline Expectoration* & $49(89.1)$ & $6(10.9)$ & $<0.001$ & $0.13(0.04-0.38)$ \\
\hline Weight Loss ${ }^{\dagger}$ & $25(89.3)$ & $3(10.7)$ & 0.03 & $0.25(0.06-0.96)$ \\
\hline Dyspnoea $^{\dagger}$ & $13(86.7)$ & $2(13.3)$ & 0.33 & $0.40(0.08-1.97)$ \\
\hline Lymph Nodes Alteration $^{+}$ & $0(00.0)$ & $6(100.0)$ & $<0.001$ & $\neq$ \\
\hline $\mathrm{HIV}^{+}$ & $7(100.0)$ & $0(00.0)$ & 0.18 & $\neq$ \\
\hline Comorbidities* & $24(75.0)$ & $8(25.0)$ & 1.00 & $1.00(0.36-2.72)$ \\
\hline Previous TB treatment $^{\dagger}$ & $32(91.4)$ & $3(8.6)$ & 0.005 & $0.16(0.04-0.62)$ \\
\hline Bacilloscopic screening* & $42(85.7)$ & $7(14.3)$ & 0.009 & $0.26(0.09-0.74)$ \\
\hline Mycobacterium culture* & $35(68.6)$ & $16(31.4)$ & 0.10 & $2.36(0.82-6.78)$ \\
\hline Tuberculin skin test* & $22(61.1)$ & $14(38.9)$ & 0.01 & $3.5(1.27-9.59)$ \\
\hline Sputum collected* & $50(87.7)$ & $7(12.3)$ & $<0.001$ & $0.14(0.05-0.43)$ \\
\hline Bronchoalveolar liquid collected $^{+}$ & $4(100.0)$ & $0(00.0)$ & 0.56 & $\neq$ \\
\hline Outcome (hospital discharge) ${ }^{\dagger}$ & $53(72.6)$ & $20(27.4)$ & 0.332 & $2.45(0.50-11.85)$ \\
\hline
\end{tabular}

Note: * Chi-square; ${ }^{+}$Fisher's exact test; ${ }^{\ddagger}$ Not possible to calculate due to low values in the matrix; TB-Tuberculosis.

Table 3 - Association of children and adolescents' features and mixed-type Tuberculosis registered in the medical files, Fortaleza, Ceara, Brazil, 2018

\begin{tabular}{|c|c|c|c|c|}
\hline \multirow{2}{*}{ Features } & \multicolumn{2}{|c|}{ Mixed-type TB } & \multirow{2}{*}{$\begin{array}{c}p \\
\text { value }\end{array}$} & \multirow{2}{*}{$\begin{array}{c}\text { Odds Ratio } \\
(95 \% \mathrm{Cl})\end{array}$} \\
\hline & No (\%) & Yes (\%) & & \\
\hline Sex $(\text { Female })^{\dagger}$ & $35(89.7)$ & $4(10.3)$ & 0.74 & $0.68(0.18-2.53)$ \\
\hline Age Range $(>10 \text { years old })^{+}$ & $65(87.8)$ & $9(12.2)$ & 1.00 & $0.83(0.15-4.33)$ \\
\hline Skin Color $(\text { Pardo })^{*}$ & $59(92.2)$ & $5(7.8)$ & 0.03 & $0.25(0.06-0.93)$ \\
\hline Precedence (from Fortaleza) ${ }^{\dagger}$ & $28(100.0)$ & $0(00.0)$ & 0.01 & $\neq$ \\
\hline Basic Sanitation $^{+}$ & $34(82.9)$ & $7(17.1)$ & 1.00 & $\neq$ \\
\hline Fever $^{\dagger}$ & $57(87.7)$ & $8(12.3)$ & 1.00 & $0.93(0.22-3.87)$ \\
\hline Expectoration $^{\dagger}$ & $48(87.3)$ & $4(12.7)$ & 1.00 & $1.05(0.28-3.92)$ \\
\hline Weight Loss ${ }^{\dagger}$ & $26(92.9)$ & $2(7.1)$ & 0.49 & $0.43(0.88-2.16)$ \\
\hline Dyspnoea $^{+}$ & $12(80.0)$ & $3(20.0)$ & 0.39 & $2.03(0.47-8.77)$ \\
\hline Lymph Nodes Alteration $^{+}$ & $6(100.0)$ & $0(00.0)$ & 1.00 & $\neq$ \\
\hline $\mathrm{HIV}^{+}$ & $3(42.9)$ & $4(57.1)$ & 0.004 & $14.09(2.61-76.06)$ \\
\hline Comorbidities* & $27(84.4)$ & $5(15.6)$ & 0.50 & $1.54(0.43-5.52)$ \\
\hline Previous TB treatment ${ }^{\dagger}$ & $28(80.0)$ & $7(20.0)$ & 0.10 & $3.06(0.82-11.38)$ \\
\hline Bacilloscopic screening ${ }^{\dagger}$ & $46(93.9)$ & $3(6.1)$ & 0.05 & $0.25(0.06-1.02)$ \\
\hline Mycobacterium culture* & $46(90.2)$ & $5(9.8)$ & 0.36 & $0.56(0.15-2.00)$ \\
\hline Tuberculin skin test $^{\dagger}$ & $34(94.4)$ & $2(5.6)$ & 0.18 & $0.28(0.05-1.38)$ \\
\hline Sputum collected* & $51(89.5)$ & $6(10.5)$ & 0.44 & $0.61(0.17-2.19)$ \\
\hline Bronchoalveolar liquid collected $^{\dagger}$ & $4(100.0)$ & $0(00.0)$ & 1.00 & $\neq$ \\
\hline Outcome (hospital discharge) $^{\dagger}$ & $64(87.7)$ & $9(12.3)$ & 1.00 & $0.91(0.17-4.73)$ \\
\hline
\end{tabular}

Note: * chi-square; $†$ Fisher's exact test; $¥$ Not possible to calculate due to low values in the matrix; TB-Tuberculosis.

Due to the number of observations, only pulmonary TB was considered when performing binary logistic regression. After analyzing the variables, female sex, weight loss, bacilloscopic screening and sputum collected presented a $p$ value lower than
0.05 and remained in the logistic regression model. All of them had a positive association with the outcome pulmonary TB, evidenced by Exp. $B$ higher than 1. Therefore, these variables are possible predictors of pulmonary TB in children and adolescents. In Table 5 , it is possible to identify the final model of logistic regression.

Table 4 - Association of children and adolescents' features and drug-resistant Tuberculosis registered in the medical files, Fortaleza, Ceara, Brazil, 2018

\begin{tabular}{lcccc}
\hline \multicolumn{1}{c}{ Features* } & \multicolumn{2}{c}{$\begin{array}{c}\text { Drug-Resistant TB } \\
\text { No (\%) }\end{array}$} & $\begin{array}{c}\boldsymbol{p} \\
\text { Yes (\%) }\end{array}$ & $\begin{array}{c}\text { Oddd Ratio } \\
\text { (95\%Cl) }\end{array}$ \\
\hline Sex (Female) & $38(97.4)$ & $1(2.6)$ & 1.00 & $0.61(0.05-7.08)$ \\
Age Range (>10 years old) & $71(95.9)$ & $3(4.1)$ & 1.00 & $\dagger$ \\
Skin Color (Pardo) & $61(95.3)$ & $3(4.7)$ & 0.55 & $\dagger$ \\
Precedence (from Fortaleza) & $28(100.0)$ & $0(00.0)$ & 0.54 & $\dagger$ \\
Basic Sanitation & $40(97.6)$ & $1(2.4)$ & 1.00 & $\dagger$ \\
Fever & $64(98.5)$ & $1(1.5)$ & 0.16 & $0.16(0.01-1.90)$ \\
Expectoration & $53(96.4)$ & $2(3.6)$ & 1.00 & $1.20(0.10-13.85)$ \\
Weight Loss & $28(100.0)$ & $0(00.0)$ & 0.54 & $\dagger$ \\
Dyspnoea & $15(100.0)$ & $0(00.0)$ & 1.00 & $\dagger$ \\
Lymph Nodes Alteration & $6(100.0)$ & $0(00.0)$ & 1.00 & $\dagger$ \\
HIV & $7(100.0)$ & $0(00.0)$ & 1.00 & $\dagger$ \\
Comorbidities & $31(96.9)$ & $1(3.1)$ & 1.00 & $0.87(0.07-10.0)$ \\
Previous TB treatment & $32(91.4)$ & $3(8.6)$ & 0.06 & $1.09(0.98-1.21)$ \\
Bacilloscopic screening & $48(98.0)$ & $1(2.0)$ & 0.58 & $0.38(0.03-4.41)$ \\
Mycobacterium culture & $49(96.1)$ & $2(3.9)$ & 1.00 & $1.46(0.12-16.83)$ \\
Tuberculin skin test & $35(97.2)$ & $1(2.8)$ & 1.00 & $0.71(0.06-8.18)$ \\
Sputum collected & $55(96.5)$ & $2(3.5)$ & 1.00 & $1.09(0.09-12.53)$ \\
Bronchoalveolar liquid collected & $4(100.0)$ & $0(00.0)$ & 1.00 & $\dagger$ \\
Outcome (hospital discharge) & $72(98.6)$ & $1(1.4)$ & 0.07 & $0.09(0.00-1.06)$ \\
& & & & \\
\hline & & &
\end{tabular}

Note: * Fisher's exact test; ${ }^{+}$Not possible to calculate due to low values in the matrix; TB- Tuberculosis.

Table 5 - Final model of logistic regression for pulmonary Tuberculosis, Fortaleza, Ceara, Brazil, 2018

\begin{tabular}{lccccc}
\hline & & \multicolumn{5}{c}{ Odds Ratio (95\%Cl) } \\
& B & P & Exp. (B) & Lower & Upper \\
\hline Pulmonary TB* & & & & & \\
Constant & -2.73 & $<0.001$ & & & \\
Sex (Female) & 1.56 & 0.013 & 4.7 & 1.4 & 16.3 \\
Weight Loss (Yes) & 1.93 & 0.004 & 6.9 & 1.8 & 26.3 \\
Bacilloscopic screening (Yes) & 1.62 & 0.008 & 5.0 & 1.5 & 16.6 \\
Sputum collected (Yes) & 1.67 & 0.012 & 5.3 & 1.4 & 19.4 \\
\hline
\end{tabular}

Note: $p=0.784$ (Hosmer and Lemeshow); $R^{2}=0.356$ (Cox \& Snell); $R^{2}=0.480$ (Nagelkerke); Model $X^{2}=$ 38.71; TB-Tuberculosis.

\section{DISCUSSION}

In this study, different TB types were found, the most common type was pulmonary (59\%), followed by extrapulmonary (25\%), mixed (13\%) and drug resistant (3\%) forms. Similarly, different studies reported pulmonary TB as the majority of the infections, followed by the extrapulmonary type, and data on drug-resistant TB are still underestimated ${ }^{(12-13)}$. Different from this, a study in Uganda showed extrapulmonary TB as the most prevalent form ${ }^{(14)}$. Moreover, in a study ${ }^{(15)}$ conducted in Spain, it was possible to see 
that $18 \%$ of the pediatric TB forms are extrapulmonary, which are more common in this group compared with the adult population.

This study found an association of female sex, expectoration, weight loss, bacilloscopic screening and sputum collected with pulmonary TB. Even though fever did not present a statistical association with pulmonary TB, it was one of the most prevalent in the group and may be considered when investigating TB. A study in Taiwan presented that fever and/or cough are indicators ofTB. When there is the inclusion of recent weight loss and contact with a smear-positive patient, a more consistent investigation for TB can be performed ${ }^{(16)}$.

In a study conducted in Salvador and Manaus ${ }^{(17)}$ it was possible to identify that when TB is diagnosed in people under 10 years old, the symptoms and the positivity rate in the bacilloscopic screenings are less common; moreover, the transmission does not happen as occurs in adults. Starting from 10 years old, particularly from 15 years old, the TB symptoms are very similar to adult ones, which can contribute to perpetuating the transmission chain.

The evaluation of TB in children occurs after presenting suggestive symptoms (coughing, fever and weight loss, as identified in this paper) or as contact with index $\operatorname{cases}^{(18-19)}$. Moreover, there is also evidence of transmission among school pupils who share activities with an index case on a regular basis ${ }^{(20)}$. Subsequently, in order to obtain a faster and more precise diagnostic, new models are being developed such as those found in Bayesian approaches or new criteria methods ${ }^{(21-22)}$.

Some studies ${ }^{(4-5,12,23)}$ showed that the percentage of children with extrapulmonary TB is higher than the adult population, whereas adults with TB of extrapulmonary type is over $10 \%$, children and adolescents presented results ranging from $25 \%$ to $30 \%$ of all TB cases. We found conditions as being from Fortaleza, change in lymph nodes, and tuberculin skin test are somehow associated with extrapulmonaryTB.

In Campina Grande ${ }^{(24)}$, it was possible to identify that $14.5 \%$ $(n=31 / 214)$ of the cases of extrapulmonary TB in people from 0-19 years old, and $8.8 \%$ of the cases were in people under 15 years old. A study ${ }^{(25)}$ conducted with indigenous and non-indigenous children in Rondônia estimated $22.1 \%$ of the children developed extrapulmonary condition (mostly by the group of non-indigenous children from five to nine years old). The most common sites of extrapulmonary infections were pleural (44\%) and peripheral lymph nodes (24\%).

Contrasting with this study, a Spanish investigation showed HIV as the main risk for extrapulmonary TB, but presented the changes in lymph nodes as the most frequent site as well as a Colombian and Saudi Arabian study. And yet, a meta-analysis reported that even though there is an association between HIV and extrapulmonary $\mathrm{TB}$, it can be weak due to the lack of diagnostic standards ${ }^{(26-29)}$.

Additionally, when comparing both pulmonary and extrapulmonary TB, it was found that being female is a risk factor for pulmonary TB. Studies showed uncertainty on age-related TB as well as this one. Residents of rural areas are more likely to develop extrapulmonary TB. Classical TB symptoms (fever, cough, malaise and weight loss) are commonly found in the pulmonary manifestation of the disease, and the diagnostic rate is higher in the pulmonary group. In contrast, drug-resistant forms are more common in extrapulmonary $\mathrm{TB}^{(30-32)}$.

HIV plays a relevant role in TB pathogenesis by increasing the risk of developing TB disease from a latent state. In the case of this study, it was associated with mixed-type TB with an odds ratio around 14-fold. However, several studies have been investigating the importance of the childhood HIV/TB coinfection and its relevance to public health. They showed a TB risk varying from 20 to 30 -fold to those infected with HIV and predicted that up to $5 \%$ of the children with TB were also HIV positive ${ }^{(33-35)}$.

Developing countries also have an elevated incidence of the disease. For instance, it was estimated a TB incidence of 23 per 100 children living with HIV in South Africa; on the other hand, in developed countries, such as the USA, such estimation only reached 0.61 per 100 children $^{(35)}$. Mortality of HIV/TB coinfection was estimated at around 31,000 in 2015 (36).

In Brazil, the HIV/TB also plays a relevant role in children and adolescents. A time series study identified that, from 2002 to 2012, when considering only TB infection, the incidence rate for the group of 0-9 and 10-19 years old was declining. When analyzing the coinfected cases, however, there was a decline only in the 0-9 years old group, and the 10-19 years old group presented an increasing incidence ${ }^{(37)}$.

Appart from that, drug-resistant TB is a global concern and a challenge to TB management programs. Children and adolescents are part of a group of interest because their compliance with the drug regimen is dependent on external factors such as parental drug administration.

Other factors are linked to drug-resistance, such as treatment abandonment. A study conducted in Recife showed that, from the 55 cases of TB in people from 0 to 19 years old, seven presented treatment abandonment (almost 13\% of them) ${ }^{(38)}$. Another point that can lead to abandonment, and consequently drug-resistance, is the adverse effects that medication brings. In Rio de Janeiro it was possible to find side effects in $22.2 \%$ of the people from $0-19$ years old ${ }^{(39)}$.

Resistance can be verified when TB treatment shows initial improvement of the condition and, after a period of time, depletes response to such treatment ${ }^{(16)}$. A study presented large data from WHO Anti-Tuberculosis Global Project and concluded that the number of children with drug-resistant TB is largely unknown and underreported. In Brazil and other Latin-American, African and Asian developing countries, for example, data were not reported ${ }^{(40)}$.

Equally important, contact with TB patients is also a point of interest since its association with TB is evident. Risk increases if the contact has smear-positive sputum, the subject is female and sleeps in the same room as the infant; and, more importantly, if the contact is malnourished ${ }^{(41)}$. The literature stresses the importance of checking the BCG vaccination (Bacillus CalmetteGuérin) during childcare visits until six months, as well as the importance of knowing the characteristics of childhood $\mathrm{TB}^{(42)}$. These actions reinforce the important roles of health professionals, mostly nurses, in managing TB programs by breaking the disease transmission chain.

\section{Limitations of the study}

The main limitation of this study was using secondary data that was poorly registered in some medical records. Variables firstly thought for this study were removed because data could not be completely analyzed due to a high amount of missing values. Moreover, handwriting of some health professionals was difficult to interpret when files had their data recorded in paper. Because of these factors, generalization can be a challenging task. 


\section{Contributions to the field of nursing, health or public policy}

Regarding the study, it was possible to comprehend that TB in children and adolescents vary in its manifestations. In the clinical practice, nurses can have one more approach when examining the group, by understanding the difference in the findings that each condition brings. It is also important to note that health professionals will be able to think in extrapulmonary manifestations due to the high incidence of these manifestations in the studied population. Therefore, nursing care can be more centered on this specific population.

\section{CONCLUSION}

In this study, many features associated with different TB diagnosis in children and adolescents were identified in a tertiary health care institution. Some of the characteristics need to be highlighted due to their difference from the adult manifestation; for example, the female sex in pulmonary TB, Iymph nodes alterations and tuberculin skin test in extrapulmonary TB, and the high influence of HIV infection in the manifestations of mixed-type.

Moreover, by knowing the characteristics brought up by this investigation, it is possible to highlight the main points associated with TB in this group, giving a clear view of the problem in order to be further addressed. After understanding the clinical and epidemiological conditions regarding TB in children and adolescents, it can be seen that, even though TB is a well-known disease, it may manifest differently in the younger population. Therefore, health professionals would be able to identify the disease and its type earlier as well as to provide rapid and correct treatment to the population affected by this condition.

\section{REFERENCES}

1. World Health Organization (WHO). Global Tuberculosis Report 2017. Geneva: World Health Organization; 2017. 262p.

2. Ministério da Saúde (BR). Secretaria de Vigilância em Saúde. Boletim Epidemiológico: indicadores prioritários para o monitoramento do Plano Nacional pelo Fim da Tuberculose como Problema de Saúde Pública no Brasil. 2017;48(8):01-11.

3. Seddon JA, Jenkins HE, Liu L, Cohen T, Black RE, Vos T, et al. Counting children with tuberculosis: why numbers matter. Intern J Tuberc Lung Dis [Internet]. 2015 [cited 2017 Nov 14];19(12):S9-S16. Available from: https://doi.org/10.5588/ijtld.15.0471

4. Triasih R, Robertson C, Duke T, Graham SM. Risk of infection and disease with Mycobacterium tuberculosis among children identified through prospective community-based contact screening in Indonesia. Trop Med Int Health [Internet]. 2015 [cited 2017 Feb 03];20(6):73743. Available from: https://onlinelibrary.wiley.com/doi/epdf/10.1111/tmi.12484

5. World Health Organization (WHO). Global Tuberculosis Report 2016. Geneva: World Health Organization; 2016. 214p.

6. Mitano F, Sicsú AN, Sousa LO, Peruhype RC, Ballestero JGA, Palha PF. Obstacles in the detection and reportring of tuberculosis cases: a discursive analysis. Rev Bras Enferm [Internet]. 2018 [cited 30 Apr 2018]; 71(supl 1):523-30. Available from: http://www.scielo.br/pdf/reben/ v71s1/0034-7167-reben-71-s1-0523.pdf

7. Venâncio TS, Tuan TS, Nascimento LFC. Incidence of tuberculosis in the state of São Paulo, Brazil, under spatial approach. Ciênc Saúde Colet [Internet]. 2015 [cited 29 Apr 2018];20(5):1541-47. Available from: http://www.scielo.br/pdf/csc/v20n5/1413-8123-csc-20-05-01541.pdf

8. Brunello MEF, Simele-Beck MF, Orfão NH, Wysocki AD, Magnabosco GT, Andrade RLP, et al. Nursing practices in the attention to a chronic condition (tuberculosis): analysis of secondary sources. Rev Gaúcha Enferm[Internet]. 2015 [cited 2018 Mar 20];36(spe):62-9. Available from: http://www.scielo.br/pdf/rgenf/v36nspe/en_0102-6933-rgenf-36-spe-0062.pdf

9. Rodrigues ILA, Motta MCS, Ferreira MA. Social representations of nurses on tuberculosis. Rev Bras Enferm [Internet]. 2016 [cited 2018 Mar 20];69(3):498-503. Available from: http://www.scielo.br/pdf/reben/v69n3/en_0034-7167-reben-69-03-0532.pdf

10. Presidência da Republica (BR). Lei no 8069, de 13 de julho de 1990. Dispõe sobre o Estatuto da Criança e do Adolescente e dá outras Providências [Internet]. Brasilia (DF); 1990[cited 2018 May 01]. Available from: http://www.planalto.gov.br/ccivil_03/leis/l8069.htm

11. Ministério da Saúde (BR). Manual de recomendações para o controle da tuberculose no Brasil. 2011. 288p.

12. Yunda LICAD, Sepúlveda EF, Herrera KM, Moreno G. Pulmonary tuberculosis in a pediatric reference hospital in Bogotá, Colombia. Int J Mycobacteriol [Internet]. 2017 [cited 2017 Dec 03];6(3):258-63. Available from: http://www.ijmyco.org/temp/ IntJMycobacteriol63258-4936311_134243.pdf

13. Jenkins HE, Tolman AW, Yuen CM, Parr JB, Keshavjee S, Pérez-Vélez CM, et al. Incidence of multidrug-resistant tuberculosis disease in children: systematic review and global estimates. Lancet [Internet]. 2014 [cited 2017 Aug 14];383(9928):1572-9. Available from: http://www. thelancet.com/pdfs/journals/lancet/PIIS0140-6736(14)60195-1.pdf

14. Jaganath $D$, Zalwango $S$, Okware B, Nsereko M, Kisingo H, Malone L, et al. Contact investigation for active tuberculosis among child contacts in Uganda. Clin Infect Dis. 2013 [cited 2017 May 20];57(12):1685-92. Available from: https://academic.oup.com/cid/ article/57/12/1685/381702

15. Pérez RP, García BS, Peña MJM. Red Española de estudio de tuberculosis aediátrica. A la vanguardia de Europa. Rev Esp Salud Publica [Internet]. 2017 [cited 2018 Feb 10];91:e201701001. Available from: http://scielo.isciii.es/pdf/resp/v91/1135-5727-resp-91-e201701001.pdf

16. Wobudeya E, Lukoye D, Lubega IR, Mugabe F, Sekadde M, Musoke P. Epidemiology of tuberculosis in children in Kampala district, Uganda, 2009-2010; a retrospective cross-sectional study. BMC Public Health. 2015;15:967. doi: 10.1186/s12889-015-2312-2 
17. Sant'Anna CC, Schmidt CM, March MFBP, Pereira SM, Barreto ML. Tuberculosis among adolescents in two Brazilian State capitals. Cad Saúde Pública [Internet]. 2013 [cited 01 May 2018];29(1):111-6. Available from: http://www.scielo.br/pdf/csp/v29n1/13.pdf

18. Ritz N, Curtis N. Novel concepts in the epidemiology, diagnosis and prevention of childhood tuberculosis. Swiss Med Wkly [Internet]. 2014 [cited 2017 Mar 09];144:w14000. Available from: https://smw.ch/article/doi/smw.2014.14000

19. Oliwa JN, Karumbi JM, Marais BJ, Madhi SA, Graham SM. Tuberculosis as a cause or comorbidity of childhood pneumonia in tuberculosisendemic areas: a systematic review. Lancet Respir Med [Internet]. 2015 [cited 2017 Feb 08];3(3):235-43. Available from: http://www. thelancet.com/journals/lanres/article/PIIS2213-2600(15)00028-4/abstract

20. Piccini P, Venturini E, Bianchi L, Baretti S, Filidei P, Paliaga L, et al. The risk of Mycobacterium tuberculosis transmission from pediatric index cases to school pupils. Pediatr Infect Dis J [Internet]. 2017 [cited 2017 Nov 22]; 36(5):525-8. Available from: https://insights.ovid.com/ pubmed?pmid=28403060

21. Schumacher SG, Smeden MV, Dendukuri N, Joseph L, Nicol MP, Pai M, et al. Diagnostic test accuracy in childhood pulmonary tuberculosis: a Bayesian latent class analysis. Am J Epidemiol [Internet]. 2016 [cited 2017 Jul 13];184(9):690-700. Available from: https://preview.ncbi.nlm. nih.gov/pmc/articles/PMC5100832/pdf/kww094.pdf

22. Sant'Anna CC. Diagnosis of tuberculosis among children and adolescents. Pulmão RJ [Internet]. 2012 [cited 2017 May 16];21(1):60-4. Available from: http://www.sopterj.com.br/wp-content/themes/_sopterj_redesign_2017/_revista/2012/n_01/14.pdf

23. Aketi L, Kashongwe Z, Kinsiona C, Fueza SB, Kokolomami J, Bolie G, et al. Childhood tuberculosis in a Sub-Saharan tertiary facility: epidemiology and factors associated with treatment outcome. PloS One [Internet]. 2016 [cited 2017 Jun 02];11(4):e0153914. Available from: http://journals.plos.org/plosone/article?id=10.1371/journal.pone.0153914

24. Barros PG, Pinto ML, Silva TC, Silva EL, Figueredo TMRM. Epidemiological profile of extra-pulmonary tuberculosis in a municipality of Paraiba state, 2001-2010. Cad Saúde Colet [Internet]. 2014 [cited 01 May 2018];22(4):343-50. Available from: http://www.scielo.br/pdf/cadsc/ v22n4/1414-462X-cadsc-22-04-00343.pdf

25. Gava C, Malacarne J, Rios DPG, Sant'Anna CC, Camacho LAB, Basta PC. Tuberculosis in indigenous children in the Brazilian Amazon. Rev Saúde Pública [Internet]. 2013 [cited 01 May 2018];47(1):77-85. Available from: http://www.scielo.br/pdf/rsp/v47n1/11.pdf

26. Zar HJ, Workman LJ, Little F, Nicol MP. Diagnosis of pulmonary tuberculosis in children: assessment of the 2012 national institutes of health expert consensus criteria. Clin Infect Dis [Internet]. 2015 [cited 2017 Aug 24];61(Suppl-3):S173-S178. Available from: https://preview.ncbi. nlm.nih.gov/pmc/articles/PMC4583577/pdf/civ622.pdf

27. Tsai KS, Chang HL, Chien ST, Chen KL, Chen KH, Mai MH, Chen KT. Childhood tuberculosis: epidemiology, diagnosis, treatment, and vaccination. Pediatr Neonatol [Internet]. 2013 [cited 2017 Jan 27];54(5):295-302. Available from: http://www.pediatr-neonatol.com/article/ S1875-9572(13)00020-X/pdf

28. Matos TP, Kritski AL, Netto AR. Epidemiological aspects of tuberculosis in children and adolescents in Rio de Janeiro. J Pediatr (Rio J) [Internet]. 2012 [cited 2017 Mar 13];88(4):335-40. Available from: http://www.jped.com.br/conteudo/12-88-04-335/port.pdf

29. Dodd PJ, Yuen CM, Sismanidis C, Seddon JA, Jenkins HE. The global burden of tuberculosis mortality in children: a mathematical modeling study. Lancet Glob Health [Internet]. 2017 [cited 2018 Mar 08];5(9):e898-906. Available from: http://www.thelancet.com/pdfs/journals/ langlo/PIIS2214-109X(17)30289-9.pdf

30. Culqui-Lévano DR, Rodriguez-Valín E, Donado-Campos JDM. Analysis of extrapulmonary tuberculosis in Spain: 2007-2012 National Study. Enferm Infecc Microbiol Clin [Internet]. 2017 [cited 2017 Oct 12];35(2):82-7. Available from: http://www.elsevier.es/ es-revista-enfermedades-infecciosas-microbiologia-clinica-28-articulo-analysis-extrapulmonary-tuberculosis-in-spain-S0213005X16301483

31. Al-Hajoj S, Shoukri M, Memish Z, Alhakeem R, Alrabiah F, Varghese B. Exploring the sociodemographic and clinical features of extrapulmonary tuberculosis in Saudi Arabia. PloS One [Internet]. 2015 [cited 2017 Apr 14];10(2):1-11. Available from: http://journals.plos. org/plosone/article?id=10.1371/journal.pone.0101667

32. Naing C, Mak JW, Maung M, Wong SF, Kassim AIBM. Meta-Analysis: The association between HIV infection and extrapulmonary tuberculosis. Lung [Internet]. 2013 [cited 2017 Apr 14];191(1):27-34. Available from: https://www.ncbi.nlm.nih.gov/pubmed/23180033

33. Devrim I, Aktürk H, Bayram N, Apa H, Tulumoğlu Ş, Devrim F, et al. Differences between pediatric pulmonary and extra-pulmonary tuberculosis: a warning sign for the future. Mediterr J Hematol Infect Dis [Internet]. 2014 [cited 2017 Jun 07];6(1):e2014058. Available from: http://www.mjhid.org/index.php/mjhid/article/view/2014.058/pdf_9

34. Sepulveda EF, Yunda LI, Herrera KM, Moreno G. Extrapulmonary tuberculosis in Colombian children: Epidemiological and clinical data in a reference hospital. Int J Mycobacteriol [Internet]. 2017 [cited 2017 Nov 12];6(2):132-7. Available from: http://www.ijmyco.org/temp/ IntJMycobacteriol62132-5425722_150417.pdf

35. Venturini E, Turkova A, Chiappini E, Galli L, Martino MD, Thorne C. Tuberculosis and HIV co-infection in children. BMC Infect Dis [Internet]. 2014 [cited 2017 Mar 25];14(Suppl 1):S5. Available from: https://www.ncbi.nlm.nih.gov/pmc/articles/PMC4016474/pdf/1471-2334-14-S1-S5.pdf

36. Hailu D, Abegaz WE, Belay M. Childhood tuberculosis and its treatment outcomes in Addis Ababa: a 5-years retrospective study. BMC Pediatr [Internet]. 2014 [cited 2017 Dec 08];14:61. Available from: http://www.biomedcentral.com/1471-2431/14/61

37. Gaspar RS, Nunes N, Nunes M, Rodrigues VP. Temporal analysis of reported cases of tuberculosis and tuberculosis-HIV coinfection in Brazil between 2002 and 2012. J Bras Pneumol [Internet]. 2016 [cited 01 May 2018]; 42(6):416-22. Available from: www.scielo.br/pdf/jbpneu/ v42n6/1806-3713-jbpneu-42-06-00416.pdf 
38. Silva CCAV, Andrade MS, Cardoso MD. Factors associated with tuberculosis treatment default in individuals monitored in health reference units of the city of Recife, Pernambuco State, Brazil, from 2005 to 2010. Epidemiol Serv Saúde [Internet]. 2013 [cited 28 Apr 2018];22(1):7785. Available from: http://scielo.iec.gov.br/pdf/ess/v22n1/v22n1a08.pdf

39. Damasceno GS, Guaraldo L, Engstrom EM, Theme Filha MM, Souza-Santos R, Vasconcelos AGG et al. Adverse reactions to tuberculosis drugs in Manguinhos, Rio de Janeiro, Brazil. Clinics [Internet]. 2013 [cited 30 Apr 2018];68(3):329-37. Available from: http://www.scielo.br/pdf/clin/ v68n3/a09v68n3.pdf

40. Dodd PJ, Gardiner E, Coghlan R, Seddon JA. Burden of childhood tuberculosis in 22 high-burden countries: a mathematical modelling study. Lancet Glob Health [Internet]. 2014 [cited 2017 May 17];2(8):e453-e459. Available from: http://www.thelancet.com/pdfs/journals/langlo/ PIIS2214-109X(14)70245-1.pdf

41. Hamzaoui A, Yaalaoui S, Cherif FT, Saidi LS, Berraies A. Childhood tuberculosis: a concern of the modern world. Eur Respir Rev [Internet]. 2014 [cited 2017 Aug 21];23(133):278-91. Available from: http://err.ersjournals.com/content/errev/23/133/278.full.pdf

42. Fusco APB, Arcêncio RA, Yamamura M, Palha PF, Reis AA, Alecrim TFA, et al. Spacial distribution of tuberculosis in a municipality in the interior of São Paulo, 2008-2013. Rev Latino-Am Enfermagem [Internet]. 2017 [cited 01 May 2018];25:e2888. Available from: http://www. scielo.br/pdf/rlae/v25/0104-1169-rlae-25-e2888.pdf 